\title{
Measuring the effects of layout upon visitors' spatial behaviors in open plan exhibition settings
}

\author{
John Peponis, Ruth Conroy Dalton \\ College of Architecture, Georgia Institute of Technology, 247 4th Street, Atlanta, GA 30332-0155, \\ USA; e-mail: john.peponis@arch.gatech.edu
}

Jean Wineman

A. Alfred Taubman College of Architecture and Urban Planning, University of Michigan, 2000 Bonisteel Boulevard, Ann Arbor, MI 48109-2069, USA; e-mail: jwineman@umich.edu

Nick Dalton

Georgia Regional Transportation Authority, 245 Peachtree Center Avenue NE, Atlanta, GA 30303, USA; e-mail: sheep@ovinity.co.uk

Received 5 July 2003; in revised form 30 October 2003

\begin{abstract}
Two arguments are made based on the analysis of traveling science exhibitions. First, sufficiently refined techniques of spatial analysis allow us to identify the impact of layout upon visitors' paths and behaviors, even in moderately sized open plans which afford almost random sequences of movement and relatively unobstructed visibility. Specifically, contact with exhibits is associated with their relative accessibility while active engagement is associated with exhibit crossvisibility. Second, newly developed or adapted techniques of analysis allow us to make a transition from modeling the mechanics of spatial movement (the way in which movement is affected by the distribution of obstacles and boundaries) to modeling the manner in which movement registers additional aspects of visual information, particularly the arrangement of exhibits according to conceptual organizing themes. The advantages of such purely spatial modes of analysis extend into providing us with a sharper understanding of some of the underlying constraints within which exhibition content is conceived and designed.
\end{abstract}

\section{Introducing the question: how do permissive open layouts influence patterns of exhibition exploration?}

This paper presents new research on the relationship between visitor behavior and layout in science exhibition settings. Previously published studies using techniques similar to the ones that are used in this study deal with either complex museum environments (Choi, 1999; Turner et al, 2001), or other environments whose spatial structure clearly constrains and channels movement choices and movement sequences in various ways (Conroy Dalton, 2003). The exhibition settings discussed here are smaller, with relatively simple open plans. Thus, it is intuitively less clear that layout will have significant effects upon the way in which visitors explore and engage exhibition contents. The theoretical and methodological challenge is to examine how exhibition space works when it seemingly imposes few nontrivial restrictions upon behavior. We take up the challenge in two parts. In the first part, we discuss how exploratory movement, visual contact, and active engagement with individual exhibits are affected by simple variables which describe the layout as a spatial pattern of visibility and accessibility arising from the distribution of objects in space. We conclude the first part by suggesting that open-ended patterns of exploration in permissive exhibition settings are subtly but precisely structured according to spatial variables. In the second part, we discuss the effects of more complex spatial variables that take into account the spatial grouping and visual coordination of exhibits according to conceptual themes. Thus, we offer descriptions of layouts which take into account the distribution of labeled objects in space, where a 'label' stands for the ascription of any property or quality to an object by virtue of a literal inscription or 
by virtue of design. This modest step allows us to discuss how observed patterns of behavior may reflect not only simple perceptual information regarding the patterns of visibility and permeability afforded by an exhibition setting, but also more complex perceptual information which relates to the cognitive content of exhibits. We conclude the second part by suggesting that otherwise open-ended patterns of exploration are sensitive to the thematic grouping of exhibits in space. Our argument contributes towards a clearer theoretical understanding of the underlying constraints that affect the conceptual and physical design of open-plan exhibitions. It also has wider methodological value in suggesting a fruitful approach to the analysis of the microscale of exhibition environments. In the remainder of this introduction we describe the empirical background to the analysis.

The analysis deals with two traveling science exhibitions, each in two different settings (figure 1). Both were created by the same organization: the Carnegie Science Center. "ZAP! surgery" presented new technologies for medical operations. "Robotics" introduced the principles that govern robotic design and function. The first exhibition was studied at The Great Lakes Science Center in Cleveland, and at the Carnegie Science Center in Pittsburgh. The second was studied at The Tech museum in San Jose and at the Great Lakes Science Center in Cleveland. All studies were completed in academic year 2000 - 01. In all instances, almost all individual exhibits were interactive, with the exception of a small number that consisted in video presentations or in visual information only. Also, although individual exhibits were designed to provide a self contained amount of information, they were also classified according to conceptual themes. For example, in the ZAP exhibition, exhibits were visually coordinated and spatially grouped according to the following themes: gamma rays, laser beams, cryosurgery, endoscopy, and ultrasound. In the case of Robotics, the presentation of exhibits referred to aspects of acting, sensing, areas of application, demonstration of use, and exhibits aimed at 'junior' visitors (see figure 1 for the spatial distribution of exhibits by theme). The conceptual themes were made more evident visually in the ZAP exhibition; in Robotics, conceptual themes were less strongly suggested, either by spatial grouping or through visual design. In both instances, however, the classification of individual exhibits by themes was objectively documented in the literature accompanying the exhibitions, whether in printed catalogues, or in web-pages.

The settings under study were simple open plans, as shown in figure 1. Many individual exhibits, or small groups of individual exhibits, were free standing, whether designed to encourage a peripheral approach (from all sides) or a directional approach (with a clear distinction between front, back, and lateral views). Other exhibits were located against the perimeter boundary, or against structural elements. The temporary exhibition area itself varied from the relatively compact and clearly bounded shape of the Great Lakes Science Center, to the more elongated shape of the Carnegie Center, or the more compact but weakly bounded space at The Tech. The few large individual exhibits, such as the ZAP cam simulation capsule in the ZAP exhibition [label S, figure 1(a) and 1(c)], or the basketball robot arm in the robotics exhibition [label $A_{1}$, figure $1(b)$ and $1(d)$ ], tended to be so located as to divide space while at the same time acting as focal points of visual attention. There was ample cross-visibility between individual exhibits. The arrangement allowed a plethora of alternative exploration paths, as there were relatively few impediments to movement. In short, the arrangements under study were not overly didactic, either in the sense of imposing a deliberate sequence to the pattern of exploration, or in the sense of framing successive visual fields to control visual groupings and cross-comparisons.

From the point of view of layout, the exhibition settings under study imply a mode of discourse where units of knowledge corresponding to individual exhibit elements are 


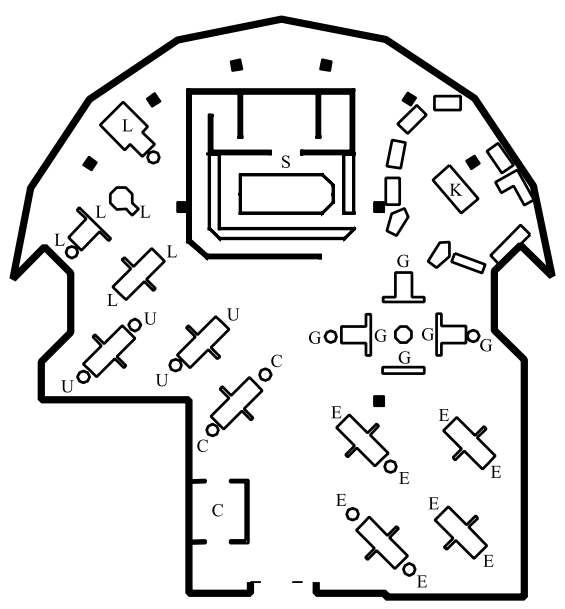

(a)

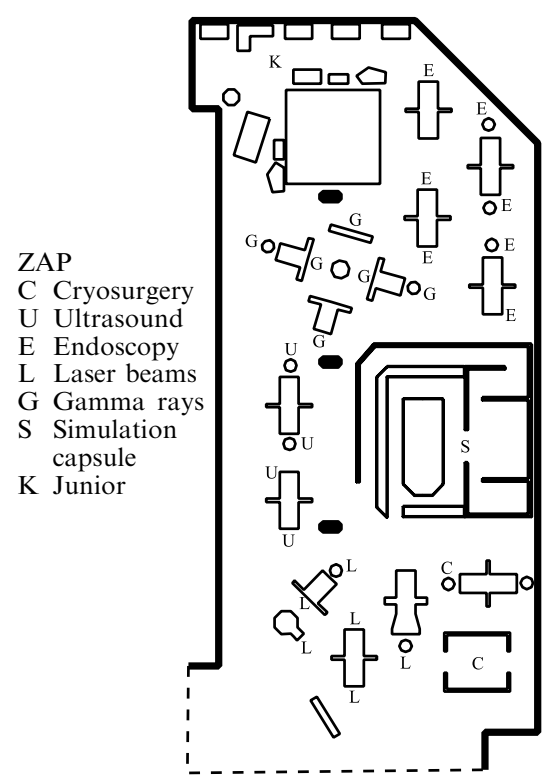

(c)

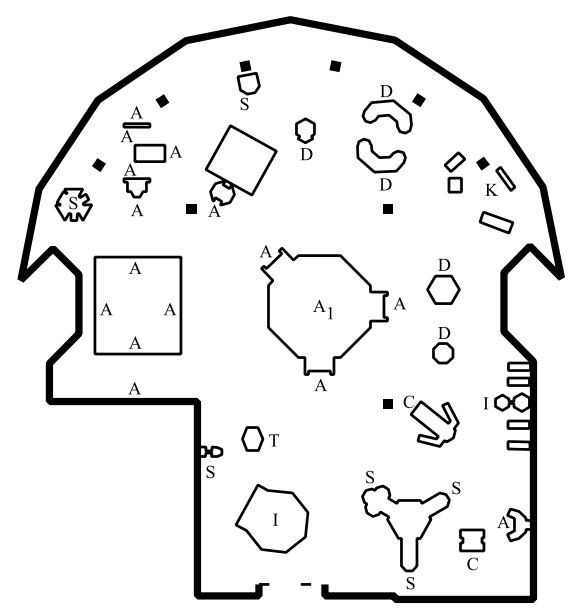

(b)

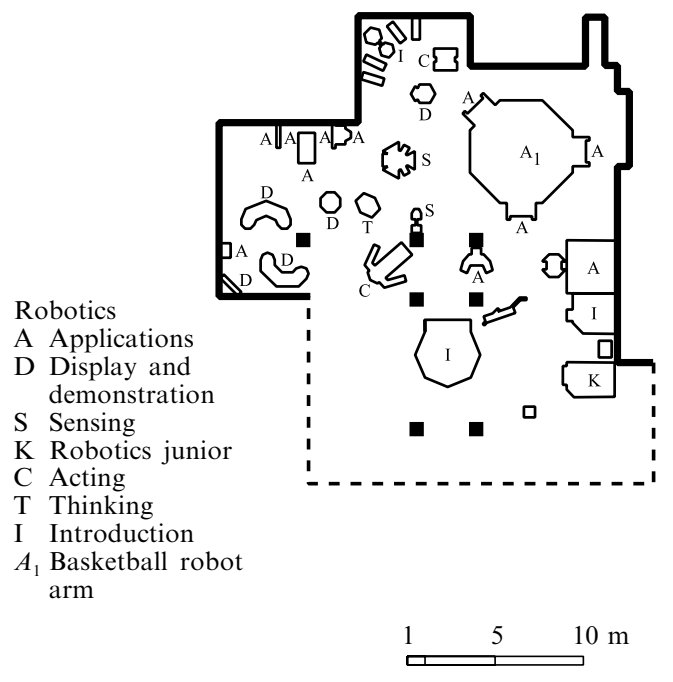

(d)

Figure 1. Diagrammatic plans of two science exhibitions in different settings: (a) ZAP! Surgery, Great Lakes Science Center, (b) Robotics, Great Lakes Science Center, (c) ZAP! Surgery, Carnegie Science Center, (d) Robotics, San Jose Tech Museum.

relatively self-contained and where the overall message arises from the quasi-random accumulation of such units. The visitor is left with the task of reconstructing the overall message by linking the conceptual contents of individual exhibits into narrative sequences. For example, some exhibits suggest that robot design involves the combination of many simple joints such that complex movements can result from the combination of simpler motions; other exhibits suggest that movements of the hand can be translated into mechanical movements through simple devices; a third group of exhibits suggests that information of some sort can be coded and translated in such a way as to cause various motions; a fourth group suggests that sensors can be used to receive information about changes in the environment: putting such ideas together, the visitor can think of robots as 
mechanisms capable not only of transferring movement but also of receiving coded instructions for movement, or of processing environmental information in order to produce such instructions. As used here, the term 'narrative' refers to the manner in which the contents of individual exhibits can be conceptually related. In many exhibitions, the narrative sequence in which information is to be received is largely dictated by the layout. In the exhibitions under study this was not the case. The openness of the layout was associated with the potential presence of many alternative ways of assembling the contents of individual exhibits into narrative sequences. The cognitive function of space in relation to the reception of exhibition content, therefore, is likely to be either weaker or more subtle. We will return to this question in our discussion of research findings.

Behavioral data were collected by direct observation in the field. One of the main aims of the research is to use such data in order to assess the attraction exercised by individual exhibits treated as potential destinations within the overall sequence of exploration of the exhibitions. About one hundred visitors were unobtrusively tracked in each setting and their paths recorded on diagrammatic plans. When a visitor path came sufficiently close to an individual exhibit, such that full awareness of the visual contents of the individual exhibit was possible, and indeed most likely, a contact was said to occur. When a visitor stopped at an individual exhibit, whether to interact with it physically or to study its visual content, an engagement was registered. Contacts include engagements but not all contacts involve engagement. Repeat contacts and repeat engagements were also registered. Each individual exhibit was thus assigned its corresponding '1st contact', '1st engagement', 'repeat contact', and 'repeat engagement' counts. Repeat counts include the 1st occurrence of the relevant behavior. In the rest of this paper, these counts will be the behavioral performance scores assigned to individual exhibits. Table 1 provides a basic quantitative profile of visitor behavior.

Table 1. Quantitative profile of visitor behavior in four exhibition settings.

\begin{tabular}{|c|c|c|c|c|}
\hline & \multicolumn{2}{|l|}{ ZAP! Surgery } & \multicolumn{2}{|l|}{ Robotics } \\
\hline & $\begin{array}{l}\text { Great Lakes } \\
\text { Science Center }\end{array}$ & $\begin{array}{l}\text { Carnegie } \\
\text { Science } \\
\text { Center }\end{array}$ & $\begin{array}{l}\text { Great Lakes } \\
\text { Science Center }\end{array}$ & $\begin{array}{l}\text { San Jose } \\
\text { Tech } \\
\text { Museum }\end{array}$ \\
\hline Number of visitors tracked & 96 & 97 & 103 & 102 \\
\hline $\begin{array}{l}\text { Average total time per visitor } \\
\text { (minutes) }\end{array}$ & 22.7 & 15.9 & 21.1 & 16.6 \\
\hline $\begin{array}{l}\text { Average total stop time per } \\
\text { visitor (minutes) }\end{array}$ & 18.8 & 12.5 & 17.4 & 12.8 \\
\hline $\begin{array}{l}\text { Average number of contacts } \\
\text { per visitor }\end{array}$ & 28.26 & 23.80 & 32.10 & 23.11 \\
\hline $\begin{array}{l}\text { Average number of } 1 \text { st contacts } \\
\text { per individual exhibit }\end{array}$ & 48.74 & 44.44 & 57.71 & 60.60 \\
\hline $\begin{array}{l}\text { Percentage of visitors contacting } \\
\text { each individual exhibit }\end{array}$ & 51 & 46 & 56 & 59 \\
\hline $\begin{array}{l}\text { Average number of repeat } \\
\text { contacts per individual exhibit }\end{array}$ & 92.52 & 80.78 & 100.68 & 98.04 \\
\hline $\begin{array}{l}\text { Average number of engagements } \\
\text { per visitor }\end{array}$ & 10.38 & 6.03 & 12.51 & 9.82 \\
\hline $\begin{array}{l}\text { Average number of } 1 \text { st engagements } \\
\text { per individual exhibit }\end{array}$ & 19.93 & 13.00 & 24.74 & 24.40 \\
\hline $\begin{array}{l}\text { Percentage of visitors engaging } \\
\text { each individual exhibit }\end{array}$ & 21 & 13 & 24 & 24 \\
\hline Average number of repeat & 31.78 & 17.63 & 38.55 & 36.88 \\
\hline
\end{tabular}
engagements per individual exhibit 
Visitors spent between 16 and 23 minutes per exhibition, depending on the setting. Each individual exhibit was contacted by between $46 \%$ and $59 \%$ and engaged by between $13 \%$ and $24 \%$ of the total number of visitors, also depending on the setting.

In order to determine the attraction exercised by individual exhibits, individual visitor paths were first described according to the sequence of contacts, including engagements, and also according to the sequence of engagements only. For example, the string of numbers $\{3,2,1,4,8,12,13,36,37,35,23,1,3,2,19\}$ describes a visitor's path as a sequence of contacts where each number stands for an individual exhibit; the string of numbers describing the same visitor's engagements is much shorter: $\{3,36,3\}$; the first string, transcribed according to themes becomes a string of characters: $\{\mathrm{C}, \mathrm{C}$, C, U, L, L, L, S, K, G, G, C, C, C, E\} (exhibits 3,2,1 belong to the same theme C, exhibit 4 belongs to theme $U$ and so on), while the second becomes $\{C, S, C\}$. The strings according to individual exhibit and the strings according to themes were the basis for computing the appropriate behavioral attraction scores for each individual exhibit, either based on contacts (including engagements) or on engagements only. Individual visitors are also characterized by the total time they spent in the exhibition. In the next section we will discuss how contact and engagement scores associated with individual exhibits are affected by simple spatial variables.

\section{The simple positional model: the statistical effects of spatial arrangement upon otherwise unconstrained search paths and engagement patterns}

At the simplest level, the spatial structure of layouts arises as objects and boundaries are placed in space. Objects and boundaries work as obstructions that limit potential visibility and/or movement. The greater the limitations upon movement, the more movement patterns are distributed according to the layout. The first model developed here is called 'positional' in that spatial structure is considered only according to the effects of positioning objects and boundaries in space. No attempt is made to recognize the additional effects of the specific informational or cognitive content of individual exhibits; nor do we deal with the ways in which individual exhibits may be related across space by such characteristics as common coloring, background lighting, and so on. However, each exhibit has a primary front face and an associated contact region, where visitors must stand in order to engage it. The spatial positioning of individual exhibits is described according to the properties of the corresponding contact regions in front of them. The overall question asked in this section is quite straightforward: how do patterns of accessibility and visibility affect the pattern of exploration, visual contact, and active engagement with exhibition contents? However, the question assumes more specific forms as individual spatial variables are defined to describe layouts and behaviors.

Two kinds of layout descriptor are used, those pertaining to the relative accessibility of individual exhibits and those pertaining to their cross-visibility. Accessibility was measured based on the analysis of visibility polygons, or isovists, drawn at foot level. A 'visibility polygon' or 'isovist' (Benedikt, 1979) encloses all the area that is directly visible $360^{\circ}$ around a vantage point. In this paper we prefer the term 'projection polygon' to recognize more explicitly the fact that such polygons can be drawn not only at eye level but also at any other level, such that what they describe is the area of space that is geometrically visible, or directly connected to the vantage point, but not necessarily the area which is literally visible to a human subject at normal eye level. Here, the area of a projection polygon (figure 2, see over) measures the amount of space from which the vantage point is directly accessible along an uninterrupted straight line: had the projection polygon been drawn at eye level many of the obstructions now registered by its shape would not come into play, as many of the exhibits are 


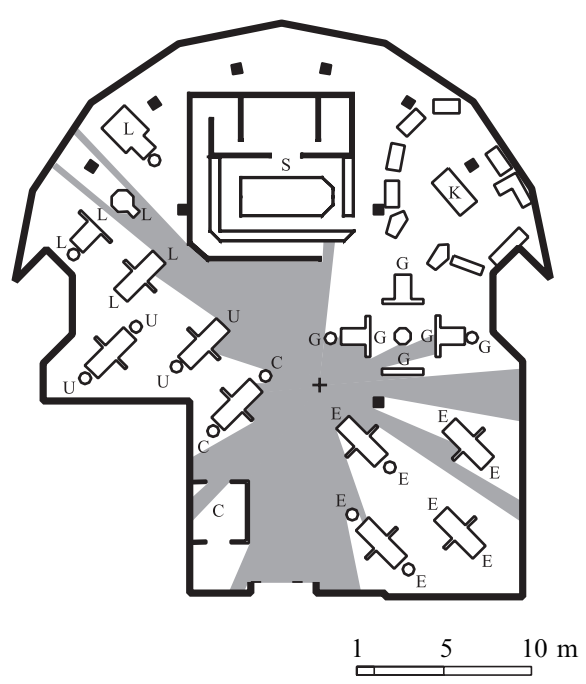

Figure 2. Example of a projection polygon at foot level for ZAP! Surgery, Great Lakes Science Center.

relatively low. The indirect accessibility of each position from other positions is described according to the pattern of intersection of projection polygons. When two polygons intersect, any point on one that does not lie on their intersection is one direction change away from the vantage point of the other. Accordingly, the directional distance of any point of a layout from any other point can be expressed as a function of the minimum number of sequentially intersecting projection polygons that must be used to move from one position to the other. Consistent with other studies, we will use the term 'mean depth' (Hillier and Hanson, 1984) to describe the directional distance from any point taken as a vantage point of a projection polygon to all other points also taken as vantage points of projection polygons.

$$
\mathrm{MD}_{i}=\sum_{\substack{j=1 \\ j \neq i}}^{k} d(i-j),
$$

where

$\mathrm{MD}_{i} \quad$ is the mean depth from vantage point $i$,

$d(i-j)$ is the number of intervening polygons between vantage points $i$ and $j$,

$k \quad$ is the number of vantage points in the system.

Area and mean depth values were computed using Omnivista software written by Nick Dalton and Ruth Conroy Dalton. Omnivista flood-fills all navigable space within each of the exhibition sites with a grid of vantage points, and generates projection polygons from these locations. Various properties are then computed for each polygon, including area; perimeter; compactness; minimum, mean, and maximum radial length; and drift (the vector distance between the vantage point and the center of gravity of the polygon). Area and mean depth proved to have greater relevance to our research. Average area and mean depth values were computed for each individual exhibit contact region, taking all the vantage points encompassed by the region into account. The grid used to flood-fill space is $30 \mathrm{~cm}$ by $30 \mathrm{~cm}$ and so each contact region encompassed several, or even many grid units. Figure 3(a) shows a layout shaded according to the area of projection polygons drawn from each square of the $30 \mathrm{~cm} \times 30 \mathrm{~cm}$ grid. Likewise, figure $3(\mathrm{~b})$ shows the same layout shaded according to the mean depth of the polygons. 


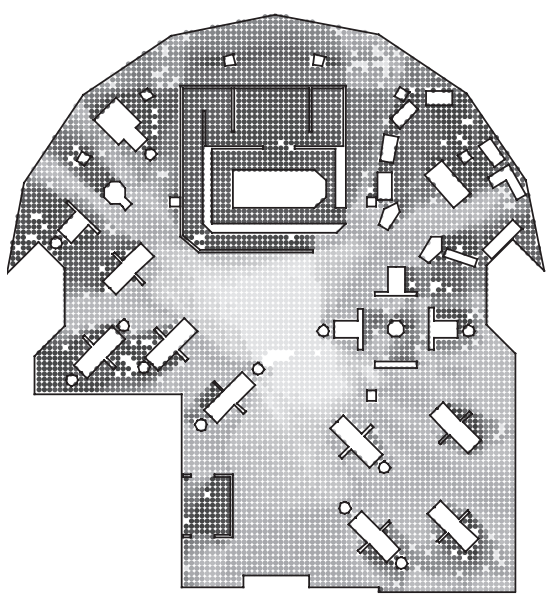

(a)
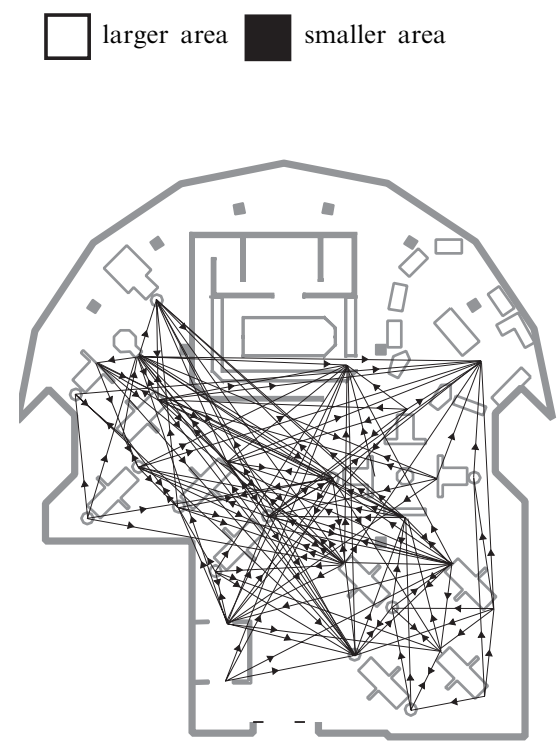

(c)

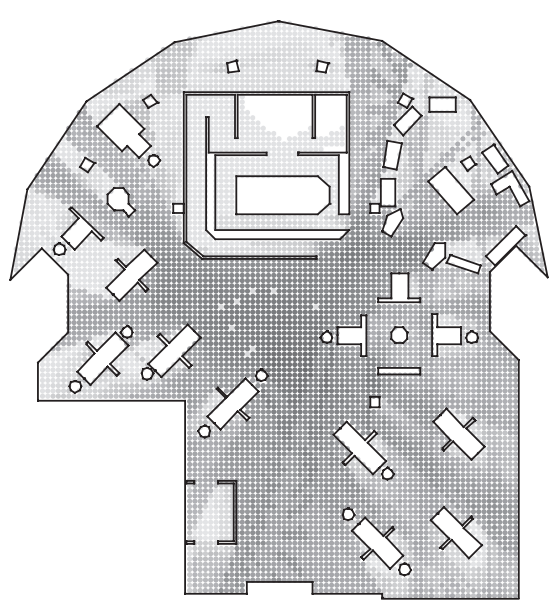

(b)
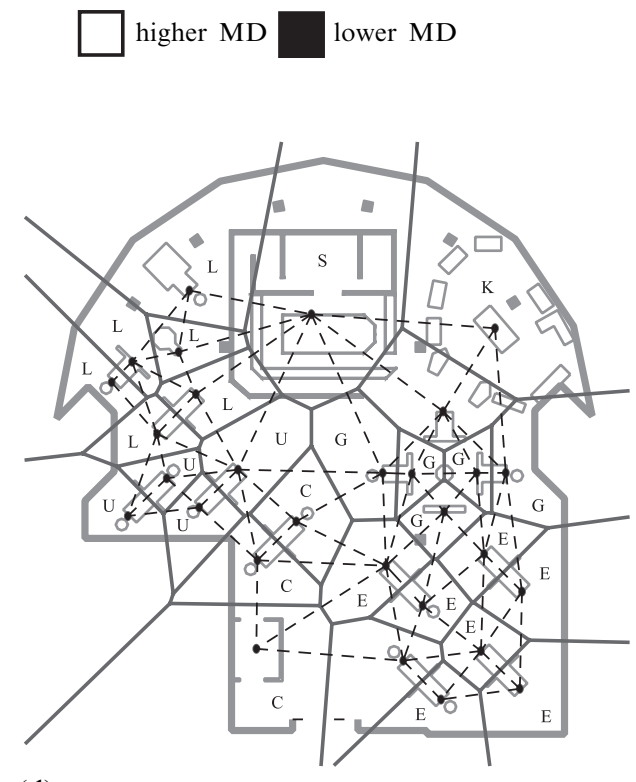

(d)

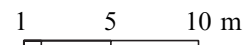

Figure 3. Visual representations of the main spatial descriptors for one of the settings, ZAP! Surgery, Great Lakes Science Center: (a) layout shaded by projection polygon area, (b) layout shaded by projection polygon mean depth (MD), (c) full cross-visibility graph, (d) Voronoi regions, Delaunay triangulation.

The cross-visibility between individual exhibits was described by directed graphs, whose nodes represent individual exhibit contact regions, and whose arcs describe the visibility of one position from another. These graphs were established empirically, in the field. The decision not to use isovists drawn at eye level was taken for two reasons. First, there is no automatic way that the computer tools used in this research would be able to recognize the presence of the contact regions of other exhibits within an isovist drawn from the contact region of a particular exhibit; the recognition would have to be established by inspection of the isovist and this would be equivalent to generating 
cross-visibility graphs in a less direct way. Second, the visibility of the front face of an exhibit from the contact region of another exhibit depends on the precise details of a layout which are more easily examined in the field. Clearly cross-visibility differs from cross-accessibility in that the front face of one exhibit could be fully visible from the contact region of another, even when movement between the two exhibits would be hindered by the presence of intervening exhibits whose height and position do not affect the particular relation of cross-visibility.

The use of directed graphs was dictated by the fact that when two exhibits are positioned in front of each other and face in the same direction, the front side of the exhibit at the back is not visible to a person engaging the exhibit at the front, while the latter is visible to a person engaging the exhibit at the back. One directed graph was used for full visibility and another for partial visibility. Full visibility was defined as being able to see another individual exhibit so as to determine its nature and contents. Partial visibility was defined as being able to see enough information to determine the presence of another individual exhibit, but not its contents or its nature. Thus, the full visibility graph is a subset of the partial visibility graph.

Cross-visibility graphs were analyzed using Pajek, software for graph analysis developed by V Baragelj and A Mrvar at the Department for Theoretical Computer Science and the Faculty of Social Sciences at the University of Ljubljana, Slovenia and available over the web (http://vlado.fmf.uni-lj.si/pub/networks/pajek/default.htm). Of the various measures computed by Pajek, the most useful for our research was the simplest, namely degree. The degree of a node measures the number of arcs incident upon it. As we deal with directed graphs, a distinction is drawn between degree 'in to' and degree 'out from' a node. In order to be consistent with the terminology of previous studies, we will use the term 'connectivity' rather than degree. We will show that connectivity in to a node is a good predictor of behavior. It is important that our measure of connectivity is not confused with similar measures as applied to nondirected graphs. Figure 3(c) shows the full cross-visibility directed graph overlaid upon a sample layout.

Table 2 presents a simple quantitative profile of the four settings. It shows that each individual exhibit can be directly reached from at least $8 \%$ and up to $14 \%$ of the total exhibition area, depending on the setting. Also, no more than three direction changes are ever necessary to go from any point within an exhibition to another. With regard to cross-visibility, the table shows that between a third and two thirds of all other individual exhibits are at least partially visible from each individual exhibit. These numbers confirm the permissive and open character of these layouts with regard to the potential exploration paths taken by visitors.

The relationship between spatial and behavioral variables was studied based on linear correlation coefficients. Table 3 (over) presents correlations between the area and mean depth of projection polygons corresponding to individual exhibits and the four measures of behavioral attraction presented above, namely 1st contact, repeat contacts, 1st engagement, repeat engagements. The decision to look for linear correlations was based on a previous visual inspection of the scatter plots. Correlations are provided for three samples: first, all people observed, that is about a hundred people per setting; second, the $25 \%$ of the people who spent more time in the exhibitions; third, the $25 \%$ of the people who stayed less time. Thus, the table presents 96 correlations in total.

Contact counts are significantly and powerfully correlated with polygon area, with 22 out of 24 correlations significant at the $1 \%$ level and stronger than 0.5 (the remaining 2 correlations are significant only at the 5\% level). Correlations with mean depth are less consistent. Only 15 out of 24 correlations are significant at the $1 \%$ level and another 7 at the $5 \%$ level. The average correlation for area is 0.588 whereas for mean depth it is -0.507 (a negative correlation indicating that greater depth is associated 
Table 2. Quantitative profile of the four exhibition settings.

\begin{tabular}{|c|c|c|c|c|}
\hline & \multicolumn{2}{|l|}{ ZAP! Surgery } & \multicolumn{2}{|l|}{ Robotics } \\
\hline & $\begin{array}{l}\text { Great Lakes } \\
\text { Science Center }\end{array}$ & $\begin{array}{l}\text { Carnegie } \\
\text { Science } \\
\text { Center }\end{array}$ & $\begin{array}{l}\text { Great Lakes } \\
\text { Science Center }\end{array}$ & $\begin{array}{l}\text { San Jose } \\
\text { Tech } \\
\text { Museum }\end{array}$ \\
\hline Total exhibition area $\left(\mathrm{m}^{2}\right)$ & 724 & 707 & 724 & 498 \\
\hline $\begin{array}{l}\text { Number of individual exhibits } \\
\text { (excludes children's area) }\end{array}$ & 27 & 27 & 35 & 25 \\
\hline $\begin{array}{l}\text { Average full individual exhibit } \\
\text { cross-visibility from other } \\
\text { individual exhibits (percentage } \\
\text { of all individual exhibits) }\end{array}$ & 21.8 & 12.5 & 19.4 & 36.6 \\
\hline $\begin{array}{l}\text { Average partial individual exhibit } \\
\text { cross-visibility from other } \\
\text { individual exhibits (percentage } \\
\text { of all individual exhibits) }\end{array}$ & 41.8 & 28.9 & 51.7 & 59.9 \\
\hline $\begin{array}{l}\text { Average projection polygon area } \\
\text { (from which an individual } \\
\text { exhibit can be reached } \\
\text { directly }\left(\mathrm{m}^{2}\right)\end{array}$ & 83.24 & 54.81 & 102.93 & 58.72 \\
\hline $\begin{array}{l}\text { Average projection polygon area } \\
\text { as percentage of total area }\end{array}$ & 11.5 & 7.8 & 14.2 & 11.8 \\
\hline $\begin{array}{l}\text { Average projection polygon } \\
\text { mean depth (direction changes } \\
\text { needed to reach from any } \\
\text { position to any other) }\end{array}$ & 2.472 & 2.280 & 1.958 & 2.067 \\
\hline
\end{tabular}

with less contacts). Engagement counts are not consistently correlated with polygon properties. Only 2 out of 24 correlations with area are significant at the $1 \%$ level and another 2 at the $5 \%$ level. Only 1 correlation with mean depth out of 24 is significant at the $1 \%$ level with another 2 at the $5 \%$ level. We draw the conclusion that the most elementary consequence of the spatial arrangement of individual exhibits, namely the variation of direct accessibility, has a powerful effect on the manner in which the exhibitions are explored, as indexed by the distribution of contacts. Interestingly, layout seems to work similarly for people who stay longer and people who stay shorter lengths of time. Thus, longer lengths of stay are not associated with any pattern of spatial learning that would theoretically be detectable by better associations between spatial variables and behavioral scores. We might infer that layout structures the search pattern based on its most simple local properties, in an almost mechanical way. By contrast, the engagement of individual exhibits would appear to be a function of decisions independent of layout, decisions which may perhaps arise based on the perceptual or cognitive appeal of exhibits. Further analysis, however, suggests that even the degree to which individual exhibits are engaged is affected by spatial parameters.

Table 4 (over) presents linear correlations between the full and partial measures of individual exhibit cross-visibility (connectivity in to) and the same four measures of behavioral attraction. The decision to look for linear correlations was based upon a prior visual inspection of the scatter plots. The format and number of correlations shown are the same as in table 1. Full cross-visibility is not consistently correlated with contacts, with 11 out of 24 correlations significant at the $1 \%$ level and 4 at the $5 \%$ level. However, all of the strong and significant correlations (at 1\%) occur in the Great Lakes Science Center, not only for the ZAP but also for the Robotics exhibition. There is no way that this bias can be reliably interpreted on a small sample of cases. However, we observe that 
Table 3. Correlations between measures of the properties of projection polygons and measures of individual exhibit attraction (significance shown in parentheses).

\begin{tabular}{|c|c|c|c|}
\hline ZAP! Surgery & & Robotics & \\
\hline Great Lakes & Carnegie & Great Lakes & San Jose \\
\hline Science Center & Science Center & Science Center & Tech Museum \\
\hline
\end{tabular}

Correlation between 1st contact counts and polygon area

$\begin{array}{lllll}\text { All people } & 0.657(0.0002) & 0.592(0.0011) & 0.563(0.0004) & 0.704(0.0001) \\ \text { Long stay } & 0.541(0.0036) & 0.542(0.0035) & 0.583(0.0006) & 0.601(0.0015) \\ \text { Short stay } & 0.601(0.0009) & 0.494(0.0088) & 0.522(0.0026) & 0.671(0.0002)\end{array}$

$0.671(0.0002)$

Correlation between repeat contact counts and polygon area

$\begin{array}{lllll}\text { All people } & 0.753(0.0001) & 0.635(0.0004) & 0.426(0.0108) & 0.712(0.0001) \\ \text { Long stay } & 0.736(0.0001) & 0.511(0.0065) & 0.427(0.0165) & 0.639(0.0006) \\ \text { Short stay } & 0.581(0.0015) & 0.557(0.0025) & 0.402(0.0250) & 0.669(0.0003)\end{array}$

Correlation between 1st contact counts and polygon mean depth

$\begin{array}{lllll}\text { All people } & -0.540(0.0037) & -0.475(0.0123) & -0.458(0.0057) & -0.736(0.0001) \\ \text { Long stay } & -0.435(0.0234) & -0.442(0.0211) & -0.507(0.0036) & -0.690(0.0001) \\ \text { Short stay } & -0.490(0.0094) & -0.480(0.0113) & -0.458(0.0096) & -0.648(0.0005)\end{array}$

Correlation between repeat contact counts and polygon mean depth
All people
$-0.618(0.0006)$
$-0.506(0.0071)$
$-0.329(0.0539)$
$-0.735(0.0001)$
Long stay
$-0.620(0.0006)$
$-0.422(0.0284)$
$-0.374(0.0383)$
$-0.706(0.0001)$
Short stay
$-0.471(0.0130)$
$-0.538(0.0038)$
$-0.338(0.0632)$
$-0.641(0.0005)$

Correlation between 1st engagement counts and polygon area
All people
$0.148(0.4615)$
$0.129(0.5226)$
$0.405(0.0157)$
$0.354(0.0829)$
Long stay
$0.223(0.2631)$
$-0.009(0.9625)$
$0.367(0.0424)$
$0.571(0.0029)$
Short stay
$0.167(0.4051)$
$0.134(0.5053)$
$0.351(0.0528)$
$0.362(0.0750)$

Correlation between repeat engagement counts and polygon area
All people
$0.366(0.0605)$
$0.228(0.2528)$
$0.404(0.0161)$
$0.504(0.0183)$
$0.518(0.0080)$
Long stay
$0.276(0.1630)$
$-0.037(0.9317)$
$0.371 \quad(0.0398)$
$0.304(0.1399)$

Correlation between 1st engagement counts and polygon mean depth
All people
$-0.040(0.8422)$
$-0.021(0.9168)$
$-0.331(0.0525)$
$-0.325(0.1130)$
Long stay
$-0.137(0.4957)$
$-0.021(0.9164)$
$-0.308(0.0917)$
Short stay
$-0.093(0.6432)$
$-0.242(0.2249)$
$-0.306(0.0943)$
$-0.545(0.0048)$
$-0.388(0.0552)$

Correlation between repeat engagement counts and polygon mean depth
All people
$-0.248(0.2117)$
$-0.061(0.7634)$
$-0.307(0.0724)$
$-0.482(0.0148)$
Long stay
$-0.206(0.3037)$
$-0.008(0.9677)$
$-0.310(0.0901)$
Short stay
$-0.079(0.6962)$
$-0.242(0.2249)$
$-0.286(0.1187)$
$-0.498(0.0112)$
$-0.356(0.0810)$

the temporary exhibition area involved has a compact shape and a clearly delimited boundary, so as both to encourage cross-visibility and to filter out extraneous visual information. Partial cross-visiblity is more consistently correlated with contact counts with 16 out of 24 correlations significant at the $1 \%$ level and another at the $5 \%$ level. Once again, the correlations are mostly associated with the Great Lakes Science Center. Overall, these results suggest that cross-visibility does not affect contacts as consistently as projection polygon area.

Cross-visibility, however, has quite powerful effects upon the pattern of engagement. Full cross-visibility is correlated with engagement counts, with 11 out of 24 correlations significant at the 1\% level and another 6 at the $5 \%$ level. Only in the case of Robotics at The Tech do we not find any significant correlations. Partial cross-visibility is even more consistently related with engagement counts, with 15 correlations significant at the $1 \%$ level and another 4 at the $5 \%$ level. We draw the 
Table 4. Correlations between measures of cross-visibility into individual exhibits and measures of individual exhibit attraction (significance shown in parentheses).

\begin{tabular}{|c|c|c|c|}
\hline ZAP! Surgery & & Robotics & \\
\hline Great Lakes & Carnegie & Great Lakes & San Jose \\
\hline Science Center & Science Center & Science Center & Tech Museum \\
\hline
\end{tabular}

Correlation between 1st contact counts and full cross-visibility

$\begin{array}{lllll}\text { All people } & 0.664(0.0001) & 0.273(0.1676) & 0.694(0.0001) & 0.312(0.1287) \\ \text { Long stay } & 0.591(0.0007) & 0.432(0.0245) & 0.727(0.0001) & 0.433(0.0305) \\ \text { Short stay } & 0.537(0.0027) & 0.268(0.1760) & 0.536(0.0019) & 0.062(0.7702)\end{array}$

Correlation between repeat contact counts and full cross-visibility

$\begin{array}{lllll}\text { All people } & 0.632(0.0002) & 0.201(0.3145) & 0.624(0.0002) & 0.329(0.1083) \\ \text { Long stay } & 0.601(0.0006) & 0.276(0.1637) & 0.714(0.0001) & 0.476(0.0161) \\ \text { Short stay } & 0.488(0.0073) & 0.233(0.2432) & 0.448(0.0114) & 0.020(0.9257)\end{array}$

Correlation between 1st contact counts and partial cross-visibility

$\begin{array}{lllll}\text { All people } & 0.699(0.0001) & 0.246(0.2153) & 0.791(0.0001) & 0.595(0.0017) \\ \text { Long stay } & 0.595(0.0007) & 0.417(0.0304) & 0.818(0.0001) & 0.681(0.0002) \\ \text { Short stay } & 0.565(0.0014) & 0.266(0.1795) & 0.704(0.0001) & 0.315(0.1250)\end{array}$

Correlation between repeat contact counts and partial cross-visibility
All people
$0.682(0.0001)$
$0.203(0.3109)$
$0.718(0.0001)$
$0.595(0.0017)$
Long stay
$0.590(0.0008)$
$0.328(0.0951)$
$0.731(0.0001)$
$0.655(0.0004)$
Short stay
$0.530(0.0031)$
$0.259(0.1917)$
$0.636(0.0001)$
$0.286(0.1661)$

Correlation between 1st engagement counts and full cross-visibility
All people
$0.489(0.0071)$
$0.407(0.0354)$
$0.573(0.0007)$
$0.035(0.8677)$
Long stay
$0.461(0.0118)$
$0.538(0.0038)$
$0.640(0.0001)$
$0.270(0.1920)$
Short stay
$0.508(0.0049)$
$0.407(0.0349)$
$0.455(0.0101)$
$0.141(0.5013)$

Correlation between repeat engagement counts and full cross-visibility
All people
$0.652(0.0001)$
$0.380(0.0504)$
$0.633(0.0001)$
$0.150(0.4740)$
Long stay
$0.499(0.0059)$
$0.614(0.0007)$
$0.672(0.0001)$
$0.279(0.1765)$
Short stay
0.494 (0.0064)
0.407 (0.0349)
$0.424(0.0175)$
$0.156(0.4552)$

Correlation between 1st engagement counts and partial cross-visibility
All people
$0.474(0.0093)$
$0.300(0.1281)$
$0.665(0.0001)$
$0.413(0.0400)$
Long stay
$0.436(0.0181)$
$0.463(0.0150)$
$0.659(0.0001)$
$0.422(0.0284)$
$0.623(0.0002)$
$0.617(0.0010)$
$0.318(0.0887)$

Correlation between repeat engagement counts and partial cross-visibility
All people
0.668 (0.0001)
$0.236(0.2358)$
0.707 (0.0001)
$0.570(0.0030)$
Long stay
$0.473(0.0096)$
$0.497(0.0083)$
$0.676(0.0001)$
Short stay
$0.533(0.0029)$
$0.422(0.0284)$
$0.601(0.0004)$
$0.604(0.0014)$
$0.353(0.0832)$

conclusion that exhibits that are visible from other exhibits stand higher chances of attracting more active engagement. Furthermore, we can perhaps detect an informal pattern of spatial learning by comparing the correlations associated with visitors who stayed longer or shorter lengths of time. In 13 out of 16 cases (there are 16 pairs of correlations to be compared) the pattern of engagement of the people who spent more time in the exhibitions is more strongly associated with cross-visibility than the corresponding pattern of the people who spent less time (in 10 out of those 13 cases the correlations compared are both significant at least at the $5 \%$ level). We concluded that there is good evidence that, as people stay longer, the visibility of individual exhibits from other individual exhibits has a more detectable effect on decisions to engage individual exhibits. The term 'informal spatial learning', as used here, refers precisely to this gradual adjustment of behavior to spatial variables as the overall exploration time increases. 
Table 5. Comparative data for the first and second halves of strings representative of all visitors' paths, the shortest $25 \%$ of visitors' paths and the longest $25 \%$ visitors paths.

\begin{tabular}{|c|c|c|c|c|}
\hline & \multicolumn{2}{|l|}{ ZAP! Surgery } & \multicolumn{2}{|l|}{ Robotics } \\
\hline & $\begin{array}{l}\text { Great Lakes } \\
\text { Science Center }\end{array}$ & $\begin{array}{l}\text { Carnegie } \\
\text { Science } \\
\text { Center }\end{array}$ & $\begin{array}{l}\text { Great Lakes } \\
\text { Science Center }\end{array}$ & $\begin{array}{l}\text { San Jose } \\
\text { Tech } \\
\text { Museum }\end{array}$ \\
\hline $\begin{array}{l}\text { Length of string representating } \\
\text { all engagement strings }\end{array}$ & 10 & 4 & 12 & 9 \\
\hline $\begin{array}{l}\text { Average projection polygon area } \\
\left(\mathrm{m}^{2}\right) \text { for } 1 \text { st half of string }\end{array}$ & 65.82 & 58.72 & 101.66 & 67.31 \\
\hline $\begin{array}{l}\text { Average projection polygon area } \\
\left(\mathrm{m}^{2}\right) \text { for } 2 \text { nd half of string }\end{array}$ & 70.69 & 62.37 & 118.23 & 61.84 \\
\hline $\begin{array}{l}\text { Average projection polygon mean } \\
\text { depth for } 1 \text { st half of string }\end{array}$ & 2.39 & 2.18 & 1.956 & 2.03 \\
\hline $\begin{array}{l}\text { Average projection polygon mean } \\
\text { depth for } 2 \mathrm{nd} \text { half of string }\end{array}$ & 2.26 & 2.30 & 1.882 & 2.03 \\
\hline Full visibility for 1 st half of string & 5.4 & 6 & 8 & 10.75 \\
\hline Full visibility for 2 nd half of string & 11.4 & 11 & 8.83 & 12.5 \\
\hline $\begin{array}{l}\text { Partial visibility for } 1 \text { st half of } \\
\text { string }\end{array}$ & 13.4 & 9 & 21.83 & 19.25 \\
\hline $\begin{array}{l}\text { Partial visibility for } 2 \text { nd half of } \\
\text { string }\end{array}$ & 18.8 & 17.5 & 22.17 & 20.5 \\
\hline $\begin{array}{l}\text { Length of string representing the } \\
25 \% \text { shortest engagement strings }\end{array}$ & 3 & 1 & 9 & 6 \\
\hline $\begin{array}{l}\text { Average project polygon area }\left(\mathrm{m}^{2}\right) \\
\text { for } 1 \text { st half of string }\end{array}$ & 30.82 & na & 102.23 & 89.08 \\
\hline $\begin{array}{l}\text { Average projection polygon area } \\
\left(\mathrm{m}^{2}\right) \text { for } 2 \text { nd half of string }\end{array}$ & 30.82 & na & 125.98 & 62.17 \\
\hline $\begin{array}{l}\text { Average projection polygon mean } \\
\text { depth for } 1 \text { st half of string }\end{array}$ & 2.52 & na & 1.98 & 1.93 \\
\hline $\begin{array}{l}\text { Average projection polygon mean } \\
\text { depth for } 2 \text { nd half of string }\end{array}$ & 2.52 & na & 1.889 & 2.01 \\
\hline Full visibility for 1 st half of string & 9 & na & 8.5 & 10.33 \\
\hline Full visibility for 2 nd half of string & 9 & na & 7 & 11 \\
\hline $\begin{array}{l}\text { Partial visibility for } 1 \text { st half of } \\
\text { string }\end{array}$ & 18 & na & 23.75 & 16.67 \\
\hline $\begin{array}{l}\text { Partial visibility for } 2 \text { nd half of } \\
\text { string }\end{array}$ & 18 & na & 18 & 22.33 \\
\hline $\begin{array}{l}\text { Length of string representing the } \\
25 \% \text { longest engagement strings }\end{array}$ & 15 & 11 & 19 & 14 \\
\hline $\begin{array}{l}\text { Average projection polygon area } \\
\left(\mathrm{m}^{2}\right) \text { for } 1 \text { st half of string }\end{array}$ & 75.35 & 54.14 & 107.43 & 70.01 \\
\hline $\begin{array}{l}\text { Average projection polygon area } \\
\left(\mathrm{m}^{2}\right) \text { for } 2 \text { nd half of string }\end{array}$ & 62.96 & 45.08 & 105.26 & 60.53 \\
\hline $\begin{array}{l}\text { Average projection polygon mean } \\
\text { depth for } 1 \text { st half of string }\end{array}$ & 2.28 & 2.42 & 1.972 & 1.99 \\
\hline $\begin{array}{l}\text { Average projection polygon mean } \\
\text { depth for } 2 \mathrm{nd} \text { half of string }\end{array}$ & 2.34 & 2.63 & 1.908 & 2.08 \\
\hline Full visibility for 1 st half of string & 8.71 & 7.8 & 9 & 9.86 \\
\hline Full visibility for 2 nd half of string & 5.14 & 3.2 & 20.67 & 12.43 \\
\hline $\begin{array}{l}\text { Partial visibility for } 1 \text { st half of } \\
\text { string }\end{array}$ & 14.43 & 14.8 & 8.44 & 18.43 \\
\hline $\begin{array}{l}\text { Partial visibility for } 2 \text { nd half of } \\
\text { string }\end{array}$ & 11.71 & 7.4 & 20.78 & 19.14 \\
\hline $\begin{array}{l}\text { Length of string representing } \\
\text { all contact strings }\end{array}$ & 22 & 20 & 24 & 24 \\
\hline
\end{tabular}


Table 5 (continued).

\begin{tabular}{|c|c|c|c|c|}
\hline & \multicolumn{2}{|l|}{ ZAP! Surgery } & \multicolumn{2}{|l|}{ Robotics } \\
\hline & $\begin{array}{l}\text { Great Lakes } \\
\text { Science Center }\end{array}$ & $\begin{array}{l}\text { Carnegie } \\
\text { Science } \\
\text { Center }\end{array}$ & $\begin{array}{l}\text { Great Lakes } \\
\text { Science Center }\end{array}$ & $\begin{array}{l}\text { San Jose } \\
\text { Tech } \\
\text { Museum }\end{array}$ \\
\hline $\begin{array}{l}\text { Average projection polygon area } \\
\left(\mathrm{m}^{2}\right) \text { for } 1 \text { st half of string }\end{array}$ & 115.01 & 72.76 & 112.9 & 69.8 \\
\hline $\begin{array}{l}\text { Average projection polygon area } \\
\left(\mathrm{m}^{2}\right) \text { for } 2 \text { nd half of string }\end{array}$ & 120.67 & 57.59 & 121.9 & 63.35 \\
\hline $\begin{array}{l}\text { Average projection polygon mean } \\
\text { depth for } 1 \text { st half of string }\end{array}$ & 2.15 & 2.29 & 1.91 & 1.96 \\
\hline $\begin{array}{l}\text { Average projection polygon mean } \\
\text { depth for } 2 \text { nd half of string }\end{array}$ & 2.13 & 2.41 & 1.90 & 2.02 \\
\hline Full visibility for 1 st half of string & 10.27 & 5.2 & 8 & 11.17 \\
\hline Full visibility for 2 nd half of string & 10.09 & 4.6 & 9.08 & 10.33 \\
\hline $\begin{array}{l}\text { Partial visibility for } 1 \text { st half of } \\
\text { string }\end{array}$ & 15.64 & 9.5 & 20.17 & 18.67 \\
\hline $\begin{array}{l}\text { Partial visibility for } 2 \text { nd half of } \\
\text { string }\end{array}$ & 16.64 & 10.6 & 22.25 & 18.5 \\
\hline $\begin{array}{l}\text { Length of string representing the } \\
25 \% \text { shortest contact strings }\end{array}$ & 13 & 10 & 19 & 15 \\
\hline $\begin{array}{l}\text { Average projection polygon area } \\
\left(\mathrm{m}^{2}\right) \text { for } 1 \text { st half of string }\end{array}$ & 134.58 & 70.2 & 123.21 & 69.14 \\
\hline $\begin{array}{l}\text { Average projection polygon area } \\
\left(\mathrm{m}^{2}\right) \text { for } 2 \mathrm{nd} \text { half of string }\end{array}$ & 132.14 & 73.15 & 122.98 & 70.02 \\
\hline $\begin{array}{l}\text { Average projection polygon mean } \\
\text { depth for } 1 \text { st half of string }\end{array}$ & 2.10 & 2.30 & 1.87 & 2.00 \\
\hline $\begin{array}{l}\text { Average projection polygon mean } \\
\text { depth for } 2 \text { nd half of string }\end{array}$ & 2.92 & 2.30 & 1.87 & 1.97 \\
\hline Full visibility for 1 st half of string & 11.5 & 6.6 & 8.56 & 13.29 \\
\hline Full visibility for 2 nd half of string & 9.67 & 4.2 & 8.56 & 8.14 \\
\hline $\begin{array}{l}\text { Partial visibility for } 1 \text { st half of } \\
\text { string }\end{array}$ & 18 & 11 & 21.56 & 18.71 \\
\hline $\begin{array}{l}\text { Partial visibility for } 2 \text { nd half of } \\
\text { string }\end{array}$ & 16.67 & 8.8 & 20.67 & 18.71 \\
\hline $\begin{array}{l}\text { Length of string representing the } \\
25 \% \text { longest contact strings }\end{array}$ & 36 & 35 & 40 & 29 \\
\hline $\begin{array}{l}\text { Average projection polygon area } \\
\left(\mathrm{m}^{2}\right) \text { for } 1 \text { st half of string }\end{array}$ & 87.39 & 57.22 & 119.18 & 67.85 \\
\hline $\begin{array}{l}\text { Average projection polygon area } \\
\left(\mathrm{m}^{2}\right) \text { for } 2 \text { nd half of string }\end{array}$ & 124.92 & 47.11 & 113.85 & 64.3 \\
\hline $\begin{array}{l}\text { Average projection polygon mean } \\
\text { depth for } 1 \text { st half of string }\end{array}$ & 2.27 & 2.44 & 1.89 & 1.97 \\
\hline $\begin{array}{l}\text { Average projection polygon mean } \\
\text { depth for } 2 \text { nd half of string }\end{array}$ & 2.11 & 2.61 & 1.91 & 1.99 \\
\hline Full visibility for 1 st half of string & 8.11 & 3.76 & 9.35 & 12 \\
\hline Full visibility for 2 nd half of string & 13 & 3.88 & 7.6 & 11.27 \\
\hline $\begin{array}{l}\text { Partial visibility for } 1 \text { st half of } \\
\text { string }\end{array}$ & 14.67 & 8.82 & 21.25 & 19.57 \\
\hline $\begin{array}{l}\text { Partial visibility for } 2 \text { nd half of } \\
\text { string }\end{array}$ & 18 & 8.82 & 21 & 18.67 \\
\hline
\end{tabular}


To establish further the basic parameters of our first model, we asked whether we could detect any effects of layout upon the sequencing of contacts or engagements. A string-matching analysis program, MultiMatch developed by Conroy Dalton as an adaptation of the Levenshtein (1965) method of string matching, was used to determine the most representative paths of the sample at each exhibit site. The string-matching analysis program determines, for any set of strings, the most representative. The most representative string is defined as the one that would require the fewest transformations to be changed to represent each of the other route strings in the sample. Figure 4 shows the most representative contacts and engagement strings for one of the settings. In addition to the most representative contact and engagement strings for each setting, we also determined the most representative strings of the corresponding $25 \%$ of the sample that included the longest paths, and the $25 \%$ of the sample that included the shortest paths. Thus, six strings were derived for each setting. We checked whether the average area and the average mean depth of the projection polygons corresponding to each node were significantly different for the first and second halves of the strings (table 5). We found no such tendency. Indeed, all individual strings appeared to oscillate between more and less accessible positions, positions associated with higher and lower mean depth, throughout their length. Thus, the patterns of accessibility and directional distance have no strong effect upon the sequencing of exploration and individual exhibit engagement.

These results suggest a first conceptualization, or interpretative model, of spatial behavior as a function of layout. The more generic, but perhaps less interesting principle, is that direct accessibility affects the distribution of contacts, that is the exposure of individual exhibits to visitors. The less generic, but perhaps more interesting, principle is that as visitors stay longer they become more aware of those individual exhibits that are more visible from other individual exhibits and decide to engage them. This model would seem to be rather elementary, and suggests an openended search process which is subtly structured by spatial variables. Based on this model, it would appear that good individual exhibit design should provide relatively autonomous and self-contained information at each position, a rather obvious requirement. Also, the more critical individual exhibits should be positioned in more accessible places and made more visible from other exhibits in order to increase the probabilities

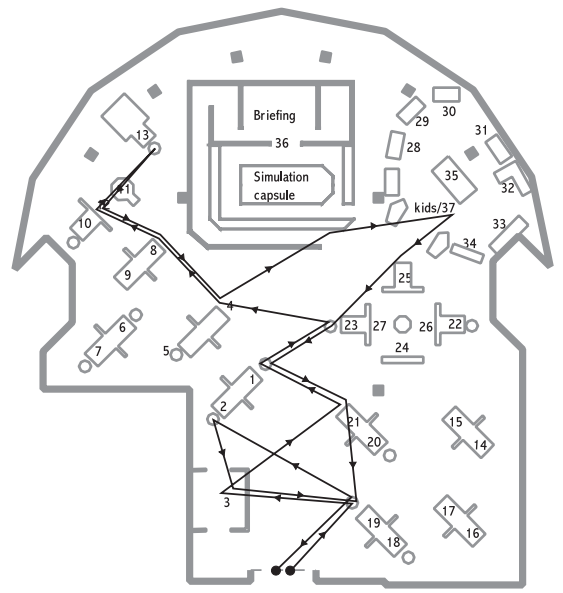

(a)

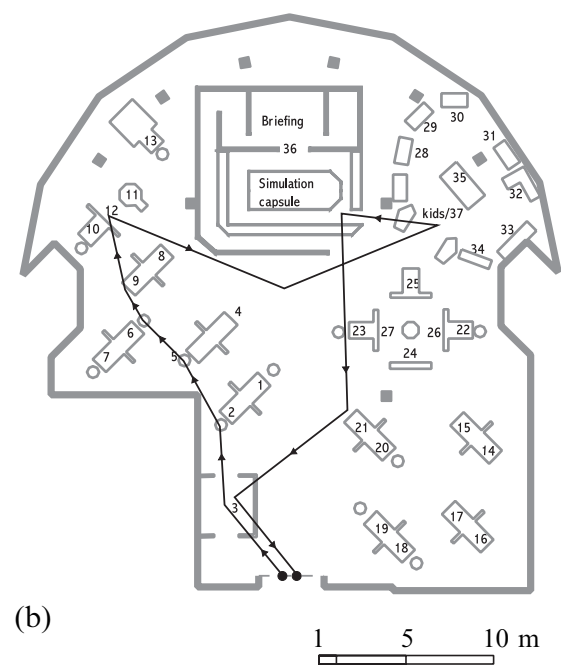

Figure 4. Most representative sequences for (a) contacts and (b) engagements for one of the settings, ZAP! Surgery, Great Lakes Science Center. 
that they will be contacted and engaged. But, as the properties of layout that affect the probability of contacts or engagements vary independently of particular path sequences, the model also suggests that good individual exhibit design should allow for the additive impact of successive engagements to be flexible and independent of the sequence or indeed the overall set of other individual exhibits that are engaged by any individual visitor. This is a far more demanding requirement but one naturally associated with open and permissive open plans and one clearly adopted by the designers of the exhibitions under study. However, the enhanced model, to be developed next, allows us to qualify and enrich these statements significantly.

\section{The compositional model: the statistical effects of labeling and the cognitive orientation of search paths and engagement patterns}

The modified conceptual model to be developed next arises from analyzing visitors' paths as strings by theme. Themes, as presented in the introduction, are essentially principles which group exhibits into sets according to their informational or cognitive content. Open-plan exhibition environments, such as those studied here, do not overly restrict movement sequences and movement choices nor impose tightly controlled frames upon the visual field; thus, the conceptual grouping of exhibits is not conveyed through directly controlling the manner in which visitors move through and view the exhibition. Instead, the conceptual grouping is expressed either through inscriptions (the explanatory texts that are affixed upon the exhibits) or through design features such as color or, indeed, through the spatial arrangement of exhibits into clusters or patterns of proximity and distance. In this section we take for granted the thematic labels associated with exhibits. We develop ways to assess whether the labeling patterns affect the sequence in which exhibits are contacted or engaged. We also develop ways to assess whether exhibits are strongly or weakly grouped in the layout according to their labels. Then we ask whether there are any correlations between the degree to which the presence of thematic labels is evident in the sequences of contacts or engagements, and the degree to which the presence of thematic labels is evident in the spatial composition of the layout. Accordingly, we call the model to be developed here compositional, to distinguish it from the positional model in which exhibits are treated merely as individual obstructions or destinations.

We use the term 'categorization' to describe the extent to which exhibits carrying the same thematic label appear sequentially within the overall string representing the path of a given visitor, or are dispersed along that path. A string is strongly categorized if individual exhibits belonging to the same theme occur in uninterrupted sequences and weakly categorized if individual exhibits belonging to the same theme are interspaced with individual exhibits belonging to other themes. Categorization arises as exhibits are positioned to take account of each other and potentially to function as collective destinations, in ways that do not directly obstruct movement.

First, we characterized strings as a whole according to whether they were strongly or weakly categorized. The aggregate categorization factor (ACF) of a string measures the extent to which individual exhibits that bear the same label are visited in succession rather than at dispersed intervals along the path taken by an individual visitor. The exhibitions were designed in such a way that each exhibit belonged to a single theme and therefore carried a single thematic label. Higher ACFs indicate that the visitor tended to visit individual exhibits bearing the same label as a group, before moving to individual exhibits bearing another label. ACFs are relativized to take into account the number of individual exhibits visited per label as well as the total length of the path (indexed by the number of individual exhibits it encompasses). The formula for the ACF of a string is:

$$
\text { if }(A=0), \quad \mathrm{ACF}=1,
$$


otherwise

$$
\mathrm{ACF}=\frac{A_{\max }-A}{A_{\max }-A_{\min }},
$$

where

$$
\begin{aligned}
& A_{\min }=k-1, \\
& A_{\max }=T, \quad \text { if }(L-N) \geqslant(N-1), \\
& A_{\max }=(T-2 N+L+1), \quad \text { if }(L-N)<(N-1),
\end{aligned}
$$

and

$k$ is the number of themes represented in the string,

$L$ is the length of the string,

$T$ is the number of transitions in the string regardless of theme,

$A$ is the number of transitions between string nodes belonging to different themes,

$N$ is the number of members of the theme with the greatest number of members within the string.

For example, for string EEEEUUCUEE,

$$
\begin{aligned}
& k=3, L=10, T=9, A=4, N=6, L-N=4, N-1=5, \\
& A_{\max }=9-12+10+1=8, A_{\min }=3-1=2, \mathrm{ACF}=(8-4) /(8-2)=0.667 ;
\end{aligned}
$$

for string EUEU,

$$
\begin{aligned}
& k=2, L=4, T=3, A=3, N=2, L-N=2, N-1=1, A_{\max }=3, \\
& A_{\min }=1, \mathrm{ACF}=(3-3) /(3-1)=0 ;
\end{aligned}
$$

for string EEE,

$$
A=0, \mathrm{ACF}=1 .
$$

Second, we characterized each label taken separately as being strongly or weakly categorized within the strings representing visitors' paths within an exhibition setting. Given the description of visitors' paths as strings by themes, we defined the categorization index per label per string (CL) as follows:

$$
\text { if }\left(2 S_{l g}-E_{l g}\right)=0, \quad \mathrm{CL}_{l g}=A_{l g},
$$

otherwise

$$
\mathrm{CL}_{l g}=\frac{A_{l g}-S_{l g}+1}{2 S_{l g}-E_{l g}},
$$

where

$\mathrm{CL}_{l g}$ is the categorization index of label $l$ in string $g$,

$A_{l g} \quad$ is the number of members of label $l$ in the string,

$S_{l g} \quad$ is the number of segments in which label $l$ occurs,

$E_{l g} \quad$ is the number of members of label $l$ that occur either first or last in the string, and can assume values 0 , or 1 , or 2 . In the special case that the string is composed of a single occurrence of label $l$, the value is 2 .

For example, for string $g=$ EEEUCU evaluated for label $\mathrm{C}$,

$$
A_{\mathrm{C} g}=1, S_{\mathrm{C} g}=1, E_{\mathrm{C} g}=0,2 S_{\mathrm{C} g}-E_{\mathrm{C} g}=2, \mathrm{CL}_{l \mathrm{C}}=(1-1+1) /(2-0)=0.5 ;
$$


for the same string evaluated for label $\mathrm{E}$,

$$
A_{\mathrm{E} g}=3, S_{\mathrm{E} g}=1, E_{\mathrm{E} g}=1,2 S_{\mathrm{E} g}-E_{\mathrm{E} g}=1, \mathrm{CL}_{\mathrm{E} g}=(3-1+1) /(2-1)=3 ;
$$

for the same string evaluated for label $\mathrm{U}$,

$$
\begin{aligned}
& A_{\mathrm{U} g}=2, S_{\mathrm{U} g}=2, E_{\mathrm{Ug}}=1,2 S_{\mathrm{Ug}}-E_{\mathrm{Ug}}=4-1=3, \\
& \mathrm{CL}_{\mathrm{Ug}}=(2-2+1) /(4-1)=1 / 3=0.333 ;
\end{aligned}
$$

for string $h=\mathrm{EEE}$, evaluated for label $\mathrm{E}$,

$$
A_{\mathrm{E} h}=3, S_{\mathrm{E} h}=1, E_{\mathrm{E} h}=2,2 S_{\mathrm{E} h}-E_{\mathrm{E} h}=2-2=0, \mathrm{CL}_{\mathrm{E} h}=3 .
$$

The formula essentially provides us with a ratio of string transitions that are internal to a label $l$, that is, transitions which connect two successive individual exhibits belonging to that label, over transitions that are external to a label $l$, that is, transitions which connect an individual exhibit belonging to a label to an individual exhibit not belonging to the same label. The overall categorization index for a label, $\mathrm{CI}_{l g}$ is defined as the average of $\mathrm{CI}_{l g}$ for all strings $g$ in which the label $l$ occurs.

Plans needed to be similarly analyzed to determine how far individual exhibits bearing the same thematic label were spatially adjacent so as to encourage sequential viewing, or dispersed. We called the property whereby individual exhibits bearing the same thematic label are spatially adjacent 'grouping'. In strongly grouped layouts, individual exhibits belonging to the same label are packed in close adjacency. In weakly grouped layouts, individual exhibits belonging to the same label are dispersed in different parts of the overall exhibition. A grouping index was developed as follows. First, a Voronoi diagram and Delaunay triangulation (O'Rourke, 1994) was obtained for each layout, after treating each individual exhibit as a point corresponding to its contact region. Delaunay triangulation was conducted using XYZ GeoBench version 5.05.(1) An example is provided in figure 3(d). The aim of this exercise was to provide us with a consistent way for determining the set of neighbors of each individual exhibit, even though the individual exhibits are irregularly distributed over the layout. Given a set of anchor points distributed over an area (here the individual exhibit interface positions) the Voronoi diagram divides space such that each region comprises all other points which are closest from a given anchor. Thus, the Voronoi diagram provides a convenient convention for assigning to each individual exhibit a convex polygon territory, such that no part of the layout remains unassigned. Here, we do not claim that the Voronoi polygons represent the 'attraction area' corresponding to an individual exhibit: it is possible that some exhibits are visible and able to attract from well outside the area assigned to them in the Voronoi diagram, as it is also possible that from some positions in that area the specific contents of the exhibits cannot easily be read. We use the Voronoi diagram only to ensure that the neighbors of an exhibit are unambiguously defined as the set of other exhibits whose Voronoi regions share a boundary with its region. Determining these neighbors is facilitated by considering the Delaunay triangulation, a graph where nodes represent points (here individual exhibit interfaces) and arcs represent shared boundaries of corresponding Voronoi regions.

The plans were analyzed to determine the number of Delaunay arcs corresponding to adjacencies between individual exhibits belonging to the same thematic label and the number of Delaunay arcs corresponding to adjacencies between individual exhibits belonging to different thematic labels. Here, the adjacencies under consideration also represent permeable connections, because we are dealing with open-plan layouts.

(1) Free downloadable software, copyright 1999, P Schorn, Department of Computer Science, Swiss Federal Institute of Technology, Zurich. 
Two grouping indexes were obtained based on the foregoing representations. The individual exhibit-sensitive grouping index, $\mathrm{GE}_{l}$ for easy reference, is the average of the ratio 'internal'/'external' Delaunay arcs, computed for each set of individual exhibits corresponding to the same label $l$. The label-sensitive grouping index, $\mathrm{GL}_{l}$ for easy reference, is the ratio 'sum of internal'/'sum of external' Delaunay arcs considering all the individual exhibits belonging to the same label. Thus, $\mathrm{GE}_{l}$ is an average of ratios, whereas $\mathrm{GL}_{l}$ is a ratio of sums.

Table 6 presents the aggregate categorization factors and the average spatial grouping indexes for the four settings. The two Robotics settings have lower values for all factors compared with the ZAP settings. This indicates a potential overall association between the spatial grouping of themes and the categorization of visitors' paths. Given that the small sample of settings does not allow a systematic testing of the implied association between these variables, the issue is explored further through an analysis by individual themes. The effect of the spatial grouping of labels upon the categorization of visitors' paths was analyzed by computing linear correlations between the categorization indices and each of the two grouping indices for each label. The decision to look for linear correlations was based on a prior visual inspection of the corresponding scatter plots. These correlations are presented in table 7. Given that the number of thematic labels in the exhibitions under study is limited, data were analyzed not only by setting but also at different levels of aggregation, in order to allow for statistical significance in the results. When all settings are considered as a single set, there is a strong and significant correlation between the thematic categorization of paths and the spatial grouping of layouts. The correlations are even stronger for engagements than for contacts. This merits some comment. Contacts must, to some extent, be sequenced according to the constraints imposed by layout: it is not possible to avoid the spaces which mediate between any origin and destination of a given transition from one individual exhibit of interest to another. Thus, it might even be hypothesized that, had visitors moved randomly, their contacts would appear thematically categorized in direct proportion to the extent that the plans were thematically grouped. Such a hypothesis would not apply to engagements with similar plausibility: engagements reflect a conscious decision which is not dictated by the pattern of adjacencies of the layout. The categorization of engagements would, therefore, be suggestive of a cognitive registration of thematic labels, unlike the categorization of contacts. The fact that when data are aggregated the spatial grouping of themes affects more powerfully the categorization of engagements than the categorization of contacts suggests that behaviors reflect the cognitive registration of thematic labels.

When we look at the analysis by setting, correlations between path categorization and layout grouping are stronger for the ZAP exhibition settings than they are for the

Table 6. Aggregate string categorization and spatial grouping factors for the four settings.

\begin{tabular}{|c|c|c|c|}
\hline ZAP! Surgery & & Robotics & \\
\hline Great Lakes & Carnegie & Great Lakes & San Jose \\
\hline Science Center & $\begin{array}{l}\text { Science } \\
\text { Center }\end{array}$ & Science Center & $\begin{array}{l}\text { Tech } \\
\text { Museum }\end{array}$ \\
\hline
\end{tabular}

Average aggregate categorization factor contacts 
Table 7. Correlations between the grouping of themes in the layout and the categorization of path strings representing contacts and engagements (significance shown in parentheses).

Grouping of theme ${ }^{\mathrm{a}} \quad$ Contacts Engagements

\begin{tabular}{lcc}
\hline All strings & $0.551(0.0024)$ & $0.605(0.0006)$ \\
GE & $0.67(0.0001)$ & $0.693(0.0001)$ \\
GL & $0.471(0.0892)$ & $0.616(0.0190)$ \\
All ZAP strings & $0.638(0.0141)$ & $0.713(0.0042)$ \\
GE & \\
GL & $0.721(0.0036)$ & $0.408(0.1480)$ \\
All Robotics strings & $0.582(0.0291)$ & $0.391(0.1670)$ \\
GE & $0.221(0.6341)$ & $0.644(0.1184)$ \\
GL & $0.462(0.2964)$ & $0.707(0.0758)$ \\
ZAP Great Lakes Science Center strings & \\
GE & $0.715(0.0710)$ & $0.586(0.1665)$ \\
GL & $0.798(0.0316)$ & $0.725(0.0654)$ \\
ZAP Carnegie Science Center strings & \\
GE & $0.691(0.0855)$ & $0.338(0.4579)$ \\
GL & $0.621(0.1366)$ & $0.416(0.3528)$ \\
Robotics Great Lakes Science Center strings & \\
GE & $0.887(0.0078)$ & $0.515(0.2371)$ \\
GL & $0.723(0.0663)$ & $0.470(0.2874)$ \\
Robotics The Tech strings &
\end{tabular}

${ }^{a} \mathrm{GE}$-individual exhibit-sensitive grouping index, GL-label-sensitive grouping index.

Robotics settings. In fact, in the Robotics settings the correlation between categorization and grouping is only significant with respect to contacts, not with respect to engagements. This is consistent with the fact that, in the case of the ZAP exhibition, thematic labels were not only more clearly grouped spatially, but also more clearly expressed visually, through the use of color, not only on the individual exhibits themselves, but also on surfaces in the background. However, only one of the sixteen correlations computed for individual setting is significant at $1 \%$ and only an additional one at $5 \%$. The lack of statistical significance, despite strong correlations, arises from the small number of thematic labels.

The second model developed here suggests that the process of relatively unstructured and locally driven exploration implied by the first model can be constrained by making the thematic organization of exhibits more evident. This has two kinds of implications. First, it suggests that, by developing the means for the perceptual recognition of themes, designers can influence the pattern of visitor exploration. This is of special interest because thematic differentiation can be pursued without imposition of strict exploration sequences. Second, individual exhibit design, and the corresponding layout of knowledge units over an entire exhibition, could proceed on the assumption that search patterns can either be allowed to intersect thematic groupings repeatedly (if themes are not made perceptually evident), or be channeled more systematically according to those groupings (if themes are made perceptually evident). By implication, thematically linked individual exhibits could be treated as contributing to a more constrained and structured exhibition narrative. 


\section{Discussion}

The notion that exhibition layout is intrinsically linked to visitor movement and viewing patterns has been long acknowledged and is confirmed in a number of recent studies (Bitgood and Shettel, 1996; Dobbs and Eisner, 1990; Falk and Dierking, 1992; Love, 1997; Miles, 1993; Naqvy et al, 1991; Serrell, 1997; Thomas and Caulton, 1996). The contribution of our research to this area of museum studies lies in the introduction of concepts and techniques for the analytic description of exhibition layout as a configuration. The existing literature, for example, may point to the fact that visitors (from Western cultures) favor right turns and tend to follow the right-hand wall of an exhibition; that they tend to spend more time at exhibits near the entrance than those near the exit; that they spend little time at center-island exhibits; that they spend more time at larger exhibitions than smaller ones. Such findings constitute firm evidence that layout affects visitor behavior and that spatial parameters must be taken into account when designing and setting up an exhibition. The introduction of new analytic descriptive methods and techniques can contribute further understanding of how the layout works as a whole. Furthermore, insofar as the analysis uses parametric variables, it is in principle possible to compare layouts with seemingly small differences or with differences that cannot be reduced to basic distinctions such as center and periphery. Thus, our research helps to make a transition from studies aimed at establishing that layout matters towards studies that develop theories of how layout works. Of course, the models presented here concern a particular type of layout, the open-plan science exhibition of relatively small scale. Other studies, cited in the introduction, apply similar techniques to larger scales of museum organization.

Our arguments also point to some rather more specialized issues of concern. First, they underscore that the development of techniques for describing spatial behaviors is critical to the development of theories of layout function. Once visitors' paths are transcribed as strings of various characters, whether representing individual exhibits or themes, the development of various techniques for analyzing the structure of strings is critical to our ability to enrich the systematic description of spatial behaviors. One innovation of the research reported here is that strings were analyzed not only so that behavioral scores could be assigned to particular spatial positions (the individual exhibit interfaces), but also so that the spatial structure implicit in the string could itself be treated as descriptive data in its own right.

Second, our arguments underscore the difference between looking at layouts in terms of the distribution of individual physical objects and looking at layouts in terms of labeled objects. We have, of course, sought to refine the description of the spatial patterns arising from the distribution of physical objects by using a fine grid for projection polygon analysis, and by using directed graphs to describe patterns of cross-visibility. On the other hand, however, techniques were also developed in order to capture how conceptual structures become embedded in layout design, taking the simple issue of spatial grouping as a point of departure. Our discussion of the manner in which themes are spatially defined is an elementary step in the direction of developing richer descriptions of exhibition arrangements. Further work is needed in order to model with precision the impact of other factors ranging from lighting to color.

As we focus on the microlevel of spatial arrangement and behavior in museum environments, the distinction between the positional and the compositional models becomes fundamental. In a positional model, spatial aspects of behavior are affected by the manner in which boundaries literally obstruct various kinds of connections of accessibility or visibility in order to create structures of spatial connectivity or separation, integration or segregation of objects and spaces. In a compositional model it is not so much the pattern of literal obstructions that generates spatial structure, but 
rather the way in which space is configured to stage our perception of how objects might be related. From an analytical point of view, cognitive composition can be conceptualized as the addition of relationships between objects over and above those involved with the patterns of proximity and accessibility. Whether these relationships arise from common thematic labels associated with consistent coloring, lighting, or decorative means of various sorts (all of which are present in the ZAP exhibition in varying degrees) is immaterial to this definition. The development of more precise descriptions of different principles and frameworks for composition, in the sense given to the term here, would lead to more insightful analyses of museum settings and other kinds of information-rich environments.

Acknowledgements. The research reported in the article was funded by a National Science Foundation Informal Science Education Grant, number 9911829, with Dr Jean Wineman as Principal Investigator and Dr John Peponis as co-Principal Investigator. The authors acknowledge the intellectual contribution of Dr Sonit Bafna, Georgia Institute of Technology, in framing research questions and developing research methods and the contributions of Tara Flaningam and Andre Wilson, University of Michigan, in data collection and analysis.

\section{References}

Benedikt M L, 1979, "To take hold of space: isovists and isovist fields" Environment and Planning B: Planning and Design $647-65$

Bitgood S, Shettel H H, 1996, "An overview of visitor studies" Journal of Museum Education 21(3) $6-10$

Choi Y K, 1999, "The morphology of exploration and encounter in museum layouts" Environment and Planning B: Planning and Design $26241-250$

Conroy Dalton R, 2003, "The secret is to follow your nose" Environment and Behavior 35 107- 131

Dobbs S, Eisner E, 1990, "Silent pedagogy of art museums" Curator 30217 - 235

Falk J H, Dierking L D, 1992 The Museum Experience (Whaleback Books, Washington, DC)

Hillier B, Hanson J, 1984 The Social Logic of Space (Cambridge University Press, Cambridge)

Levenshtein V I, 1965, "Binary codes capable of correcting deletions, insertions and reversals" Diklady Akademii Nauk SSR 163 845-848 (in Russian)

Love S, 1997, "Curators as agents of change", in Exhibiting Dilemmas: Issues of Representation at the Smithsonian Eds A Henderson, A L Kaeppler (Smithsonian Institution Press, Washington, DC) pp 246-261

Miles R, 1993, "Holding power: to choose time is to save time" What Research Says About Learning in Science Museums $217-20$

Naqvy A A, Venugopal B, Falk J H, Dierking L D, 1991, "The New Delhi Museum of Natural History" Curator 34(1) $51-57$

O'Rourke J, 1994 Computational Geometry (Cambridge University Press, Cambridge)

Serrell B, 1997, "Paying attention: the duration and allocation of visitor's time in museum exhibitions" Curator $40108-125$

Thomas G, Caulton T, 1996, "Communication strategies in interactive space”, in Exploring Science in Museums Ed. S Pearse (Athlone Press, London) pp 107-122

Turner A, Doxa M, O’Sullivan D, Penn A, 2001, "From isovists to visibility graphs: a methodology for the analysis of architectural space" Environment and Planning B: Planning and Design 28 $103-121$ 
